\title{
DENSITY FUNCTIONAL THEORY STUDY OF 5-PHENYL-1,3,4- OXADIAZOLE-2-THIOL AND ITS DERIVATIVES AS PHOTOSENSITIZERS FOR DYE-SENSITIZED SOLAR CELLS
}

\author{
D. Sudha ${ }^{1}$, V. Sathyanarayanamoorthi ${ }^{2}$ and K. Uthayarani ${ }^{1, \bigotimes}$ \\ ${ }^{1}$ Department of Physics, Sri Ramakrishna Engineering College, Coimbatore-641 022, \\ (Tamilnadu) India \\ ${ }^{2}$ Department of Physics, PSG College of Arts and Science, Coimbatore-641 014, \\ (Tamilnadu) India \\ Corresponding Author: uthayarani.karunakaran@srec.ac.in
}

\begin{abstract}
The cornerstone of the present study is the theoretical analysis of electronic and redox properties of 5-phenyl-1,3,4oxadiazole-2-thiol dyes using DFT with B3LYP/6-311+G $(\mathrm{d}, \mathrm{p})$ level. In this investigation, the dye properties were carried out in both the gas and solvent phases. The ground and excited state oxidation potentials, as well as electron injection from the dyes to semiconductor $\mathrm{TiO}_{2}$, are reported. The calculation shows that all of the dyes can potentially be good photosensitizers in DSSC. Their LUMOs lie over the $\mathrm{E}_{\mathrm{cb}}$ of $\mathrm{TiO}_{2}$ and their $\mathrm{HOMO}$ lie under the reduction potential energy of the electrolytes corresponding to the ability of electron transfer from the dye excited state to $\mathrm{TiO}_{2}$. The study of structural, electronics and optical properties for these compounds could help to design more efficient functional photovoltaic organic materials.
\end{abstract}

Keywords: 5-phenyl-1,3,4-oxadiazole-2-thiol, Organic dyes, Dye-sensitized Solar Cells, Light-harvesting Efficiency, Density Functional Theory.

RASĀYAN J. Chem., Vol. 14, No.3, 2021

\section{INTRODUCTION}

Dye-sensitized solar cells (DSSCs) have been regarded as one of the most promising next-generation photovoltaic cells due to their potentially low fabrication costs, easy production, and flexibility compared to traditional silicon-based solar cells. ${ }^{1}$ The sensitizer plays a significant role in improving the efficiency of DSSCs. Therefore, considerable synthetic works have been carried out on Ru-based sensitizers ${ }^{2,3}$ and metalfree organic dye sensitizers. ${ }^{4-9}$ The dye-sensitized solar cell (DSSC) uses molecules to absorb photons and separates the two functions of light-harvesting and charge-carrier transport. The advantage of this kind of solar cell is that it is compatible with various supporting materials and can be produced under mild conditions. ${ }^{10}$

The basic structure of most of the organic sensitizers is made of a donor (D), a bridge (B, typically a $\pi$ spacer), and an acceptor (A) moiety, which are usually combined following D- $\pi$-A rod-like configuration to improve the efficiency of the UV/vis photoinduced intramolecular charge transfer (ICT). Generally, the critical factors that influence the sensitization are (i) the excited-state redox potential has to match the energy of the conduction band (CB) edge of the semiconductor; (ii) the highest occupied molecular orbital (HOMO) must fit redox potential, and the lowest unoccupied molecular orbital (LUMO) has to be higher in energy; (iii) a huge light-harvesting ability of the dye is crucial to get a substantial photocurrent response; (iv) the good conjugation across the donor and anchoring group determines the large charge transfer (CT) character of the electronic transition; (v) the electronic coupling strength between dye's LUMO and the semiconductor $\mathrm{CB}$ is, of course, a key property for efficient electron injection from the dye onto the semiconductor surface. Note that in general, the major factors leading to a low conversion efficiency of many organic dyes in DSSC are the formation of dye aggregates and charge recombination between the CB electrons and the dye or the electrolyte. To further design and develop more efficient metal-free dyes for DSSCs, appropriate DBA systems are needed whose properties can be finely tuned by applying adequate 
structural modifications. Recently, it has been found that triphenylamine (TPA)-like moieties and a cyanoacetic acid group are units of choice as electron donor and electron acceptor/anchoring groups, respectively. ${ }^{11-13}$ Indeed, the TPA moiety is expected to greatly confine the cationic charge from the semiconductor surface and efficiently hamper the recombination. TPA also shows a huge steric hindrance and can therefore prevent unfavorable dye aggregation at the semiconductor surface. ${ }^{14}$

The interest in organic sensitizing dyes for usage in DSSCs has been growing quickly over the past few years. All-organic dyes have shown promising potential as an effective sensitizer in dye-sensitized solar cells (DSSCs). ${ }^{15}$ The design concept of all-organic dyes to improve light-to-electric-energy conversion is discussed based on absorption, electron injection, dye regeneration, and recombination. In DSSCs, the photosensitizer is one of the most important components influencing solar cell performance, because the choice of sensitizer determines the photoresponse of the DSSC and initiates the first steps of photon absorption and therefore the subsequent electron transfer process. In addition to standard Ru-complex sensitizers, metal-free analogs within the sort of organic dyes have also been investigated in DSSCs. The photovoltaic performance of organic dye sensitizers has continually improved. ${ }^{16}$

To achieve higher performances for solar cells based on organic dyes, comparable to those for solar cells based on Ruthenium complexes, sophisticated molecular design of organic dyes is required. For this purpose, 5-Phenyl-1,3,4-Oxadiazole-2-thiol dye and its derivatives were selected to improve both solar cell performance and the long-term stability of the solar cells. Based on the detailed molecular design of 5Phenyl-1,3,4-Oxadiazole-2-thiol dye and their derivatives, the photovoltaic performance was reported.

\section{Computational Methods}

\section{EXPERIMENTAL}

Two powerful methodologies namely ab initio and density functional theory (DFT) have been developed to compute solutions for the many-electron systems. DFT/Time-dependent DFT (TDDFT) is the most often used theoretical approach to investigate the ground state and excited state properties of photo-sensitizer. DFT is the method of choice for large systems and even for molecular dynamics calculations. It is more computationally efficient than the Hartree-Fock methods. ${ }^{17}$ The accuracy of DFT is based on approximations and so-called exchange-correlation functional and it is computed through various models and approximate methods.

In the present work, 5-Phenyl-1,3,4-oxadiazole-2-thiol dye molecule and newly designed dyes were performed to determine geometrical electronic structure and spectra using Density Functional theory. All the calculations were performed both in the gas and solvent phase using Gaussian 09 package. ${ }^{18}$ The basis set B3LYP function and 6-311+G(d,p) has been used. The polarizable Continuum Model (PCM) has been used for the study of solvent effects.

This section, it is focused on the evaluation of the electrochemical properties of the dyes in their excited states. The free energy change for electron injection onto a titanium dioxide surface is:

$$
\Delta G^{\text {inject }}=E_{o x}^{d y e *}-E_{C B}^{T i O 2}
$$

Where, $E_{o x}^{d y e^{*}}$ is the oxidation potential of the dye in the excited state, and $E_{C B}^{T i O 2}$ is the energy of the conduction band of the $\mathrm{TiO}_{2}(-4.0 \mathrm{eV})$ semiconductor. ${ }^{19}$ The model used for the evaluation of $E_{\text {ox }}^{\text {dye* }}$ implies that the electron injection occurs from the unrelaxed excited state. For this reaction path, the excited-state oxidation potential can be extracted from the redox potential of the ground state $E_{o x}^{d y e}$, and the absorption energy associated with the photo-induced ICT $\left(\lambda_{\max }^{I C T}\right)$ according to:

$$
E_{\text {ox }}^{d y e *}=E_{\text {ox }}^{d y e}-\lambda_{\text {max }}^{I C T}
$$

Where, $\lambda_{\max }^{I C T}$ is the energy of the intermolecular charge transfer.

The efficiency of DSSC is the performance of the dyes in responsibility to the incident light. Based on the light-harvesting efficiency of the dyes, the value has to be as high as possible to maximize the photocurrent response. The light-harvesting efficiency (LHE) was determined by formula. ${ }^{20}$

$$
\mathrm{LHE}=1-10^{-f}
$$


Where $f$ is the Oscillator's strength of the dye.

\section{RESULTS AND DISCUSSION}

A systematic comparison of frontier molecular orbitals and absorption spectra of 5-phenyl-1, 3, 4oxadiazole-2-thiol, and newly designed dyes are carried out. Furthermore, the light-harvesting efficiency (LHE) and the driving force of electron injection $\left(\Delta \mathrm{G}_{\text {inject }}\right)$ are calculated. In addition, the electron coupling of 5-phenyl-1,3,4-oxadiazole-2-thiol is simulated by the DFT method to testify the electron injection efficiency. This work is expected to reveal the effect of chemical modification on the DSSCs efficiency and provide valuable guidance for developing efficiency dyes. ${ }^{21-29}$

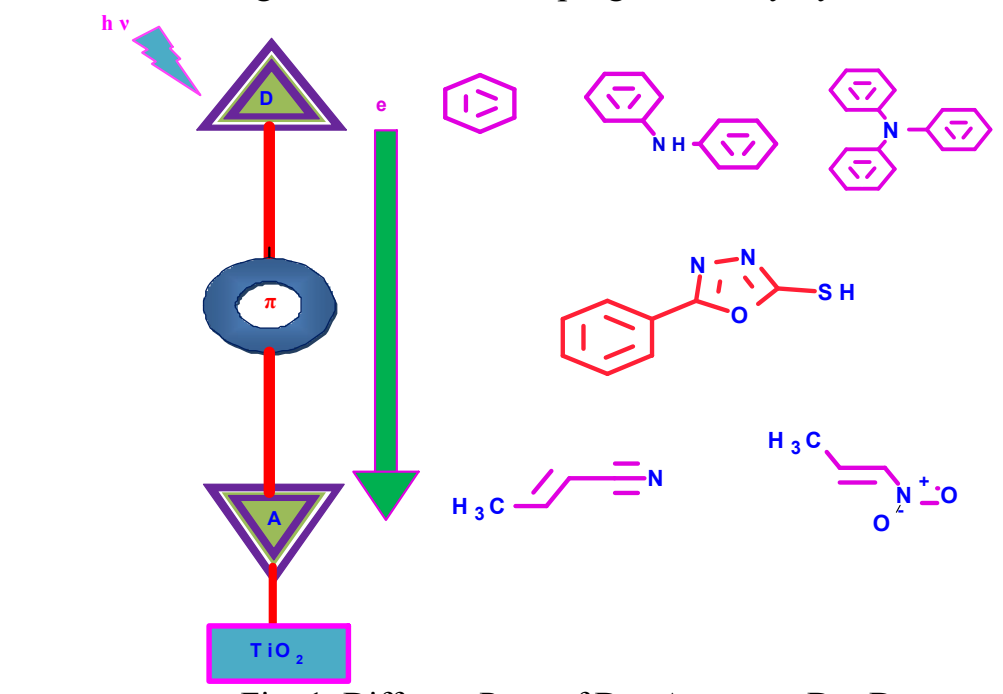

Fig.-1: Different Parts of D- $\pi$-A system, $D=$ Donor, $\pi=$ pi-spacer, $A=$ Acceptor
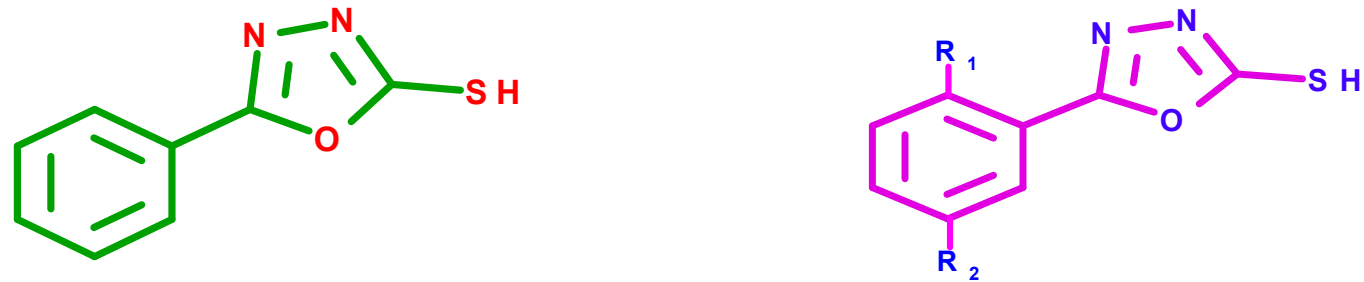

$$
\begin{array}{lll}
\text { POT1 } & \mathrm{R}_{1}=\mathrm{C}_{6} \mathrm{H}_{6} & \mathrm{R}_{2}=\mathrm{C}_{2} \mathrm{H}_{2} \mathrm{CN} \\
\text { POT2 } & \mathrm{R}_{1}=\mathrm{C}_{6} \mathrm{H}_{6} & \mathrm{R}_{2}=\mathrm{C}_{2} \mathrm{H}_{2} \mathrm{NO}_{2} \\
\text { POT3 } & \mathrm{R}_{1}=\mathrm{C}_{12} \mathrm{H}_{10} \mathrm{~N} & \mathrm{R}_{2}=\mathrm{C}_{2} \mathrm{H}_{2} \mathrm{NO}_{2} \\
\text { POT4 } & \mathrm{R}_{1}=\mathrm{C}_{12} \mathrm{H}_{10} \mathrm{~N} & \mathrm{R}_{2}=\mathrm{C}_{2} \mathrm{H}_{2} \mathrm{CN} \\
\text { POT5 } & \mathrm{R}_{1}=\mathrm{C}_{18} \mathrm{H}_{15} \mathrm{~N} & \mathrm{R}_{2}=\mathrm{C}_{3} \mathrm{H}_{2} \mathrm{O}_{2} \mathrm{CN}
\end{array}
$$

Fig.-2: Chemical Structure of 5-phenyl-1,3,4-oxadiazole-2-thiol [POT] and Newly Designed Dyes

\section{Electronic Structure}

The ground-state structure for 5-Phenyl-1,3,4 -oxadiazole- 2- thiol and newly designed dyes were carried out at the B3LYP level. The discussion based on geometrical parameters of the ground state structure is neglected. The distribution patterns of highest occupied molecular orbitals (HOMO) and lowest unoccupied molecular orbitals (LUMO) are used to study the efficiency of sensitizers and they are shown in Fig.-3 and 4 in Table-1, we have tabulated the computed HOMOs energies, LUMOs energies, and energy gap of the POT-based sensitizers at B3LYP/6-311+G(d,p) level theory.

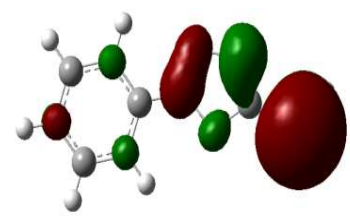

POT HOMO

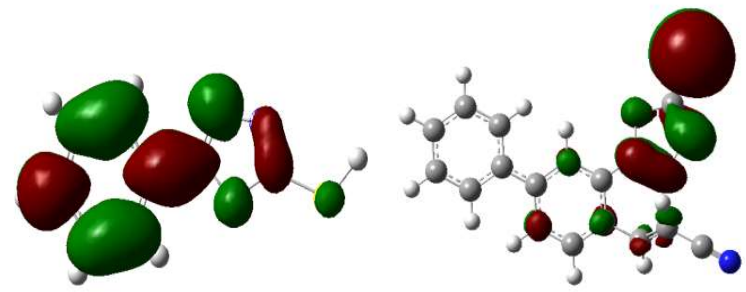

POT LUMO

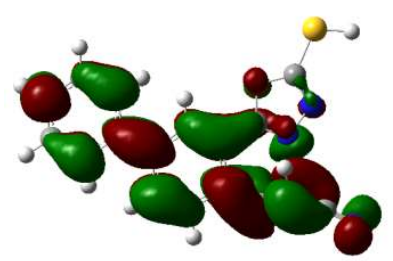

POT1 LUMO 


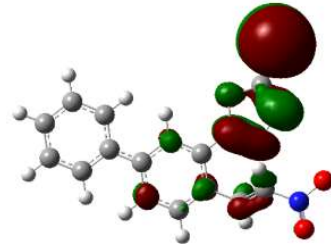

POT2 HOMO

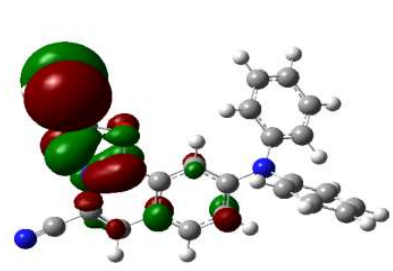

POT4 HOMO

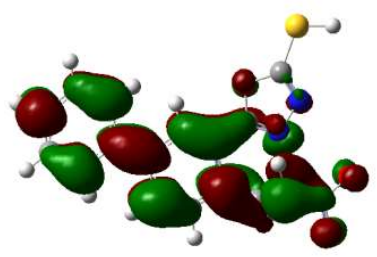

POT2 LUMO

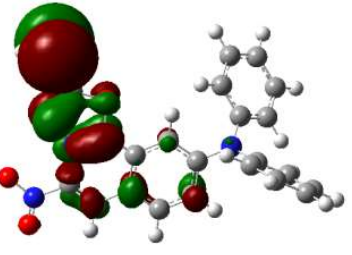

POT3 HOMO

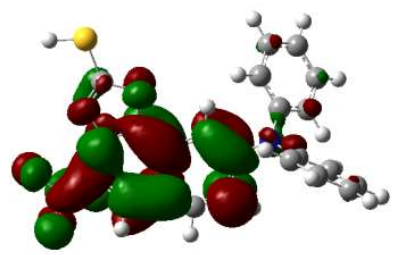

POT3 LUMO

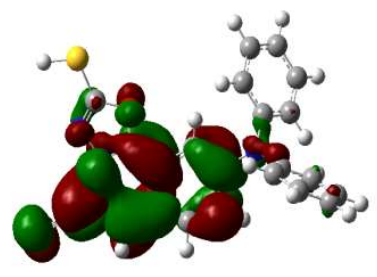

POT4 LUMO

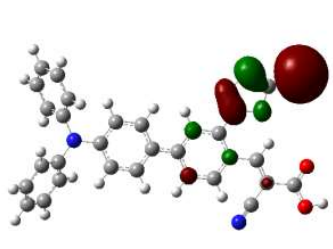

POT5 HOMO

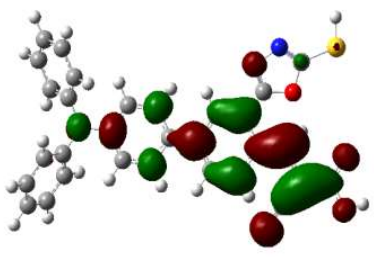

POT5 LUMO

Fig.-3: The HOMO and LUMO Distribution Pattern of Dyes at DFT / B3LYP/6-311+G* Level of Theory in Gas Phase

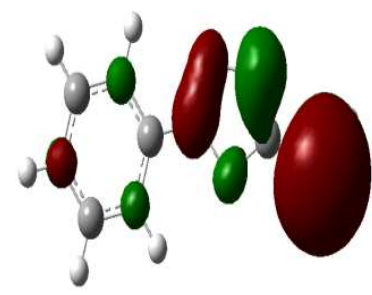

POT HOMO

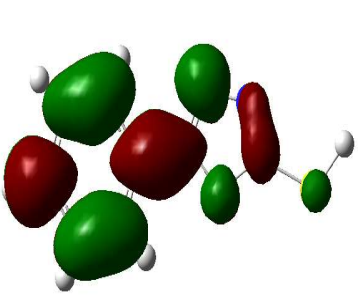

POT LUMO

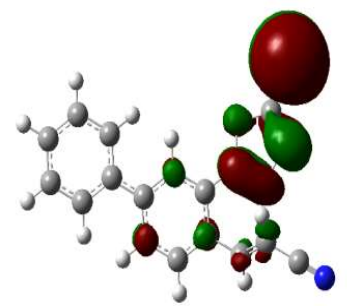

POT1 HOMO

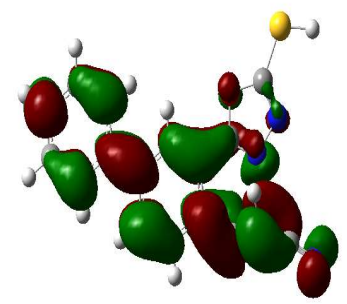

POT1 LUMO

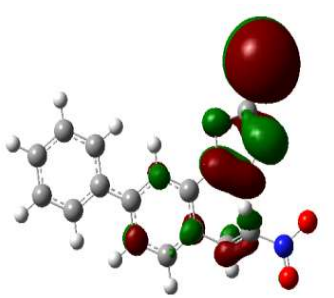

POT2 HOMO

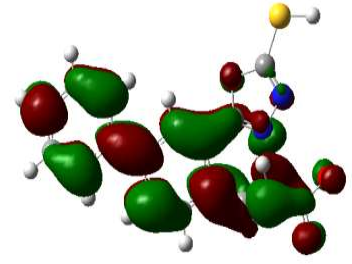

POT2 LUMO

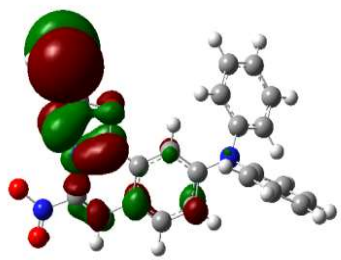

POT3 HOMO

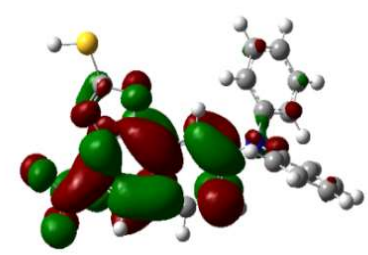

POT3 LUMO

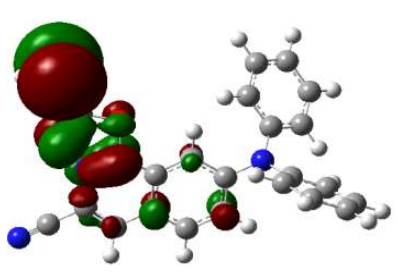

POT4 HOMO

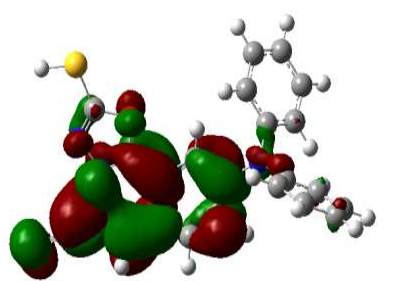

POT4 LUMO

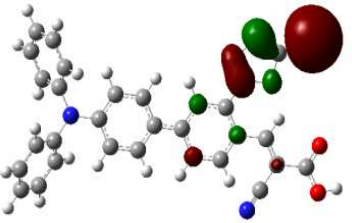

POT5 HOMO

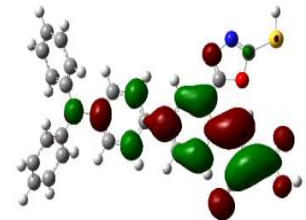

POT5 LUMO

Fig.-4: The HOMO and LUMO Distribution Pattern of Dyes at DFT / B3LYP/6-311+G* Level of Theory in PCM

The trend of HOMO energies is POT4 $>$ POT1 $>$ POT5 $>$ POT $>$ POT3 in gas phase and POT4 $>$ POT3 $>$ POT1 $>$ POT2 $>$ POT5 $>$ POT in solvent medium. Whereas LUMO energies is POT3 $>$ POT5 $>$ POT $>$ POT4 $>$ POT1 $>$ POT 2 in gas phase and POT $>$ POT $5>$ POT $4>$ POT1 $>$ POT $3>$ POT2 in solvent medium. It can also be observed that elongating the bridge $\mathrm{E}_{\mathrm{g}}$ usually decreases. The smaller energy gap of POT1, POT2 and POT4 than POT, POT3 and POT5, so those DSSCs performances of the sensitizers have been greater than the later one. In the case of solvent medium POT1, POT2, POT3 and POT4 provide better performance. 
RASĀYAN J. Chem.

Vol. 14 | No. 3 |1875-1884| July - September | 2021

Table-1: The Eномо, ELUmo and Energy Gap (Eg) of Dyes in eV at B3LYP/6-311+G Level of Theory

\begin{tabular}{c|c|c|c|r|r|r}
\hline \multirow{2}{*}{ System } & \multicolumn{3}{|c|}{ Gas Phase } & \multicolumn{3}{c}{ DMF } \\
\cline { 2 - 7 } & $\mathrm{E}_{\text {HOMO }}$ & $\mathrm{E}_{\text {LUMO }}$ & $E_{\text {gap }}$ & $\mathrm{E}_{\text {HOMO }}$ & $\mathrm{E}_{\text {LUMO }}$ & $E_{\text {gap }}$ \\
\hline POT & -6.9239 & -1.8484 & 5.0755 & -6.9871 & -1.9192 & 5.0678 \\
\hline POT1 & -6.0929 & -2.5540 & 3.5388 & -6.0739 & -2.5031 & 3.5707 \\
\hline POT2 & -6.1944 & -2.7685 & 3.4259 & -5.9664 & -2.9940 & 3.1524 \\
\hline POT3 & -7.4336 & -1.4438 & 5.9898 & -5.9664 & -2.9715 & 2.9949 \\
\hline POT4 & -5.9661 & -2.4329 & 3.5331 & -5.9269 & -2.4169 & 3.5100 \\
\hline POT5 & -6.7703 & -1.8028 & 4.9675 & -6.8026 & -1.9200 & 4.8825 \\
\hline
\end{tabular}

Considerably lowered LUMO energy levels would not only enhance the electron injection ability but also make such sensitizers unsusceptible to oxidation. The smaller $E_{\text {LUMO }}$ of POT3 and POT5 sensitizers also showed that inject electrons might be supplementarily tabulated, which would result in hindering the quenching. However, the most positive value of the energy gap is found in POT3 in the gas phase. The least value of the energy gap is found in the same dye in a solvent medium. The significance of redshift has been observed in the case of di-phenyl and tri-phenyl substituted sensitizers which revealed that it is efficient visible light sensing or absorbing sensitizers. Moreover, it is also expected that these dyes can be used as sensors having the sensing aptitudes of metal ions in the UV-vis wavelength. The energy level diagram of the HOMO and LUMO of the dyes, $E_{c b}$ of $\mathrm{TiO}_{2}$ and redox potential energy of the electrolyte, are presented in Fig.-5 and 6.
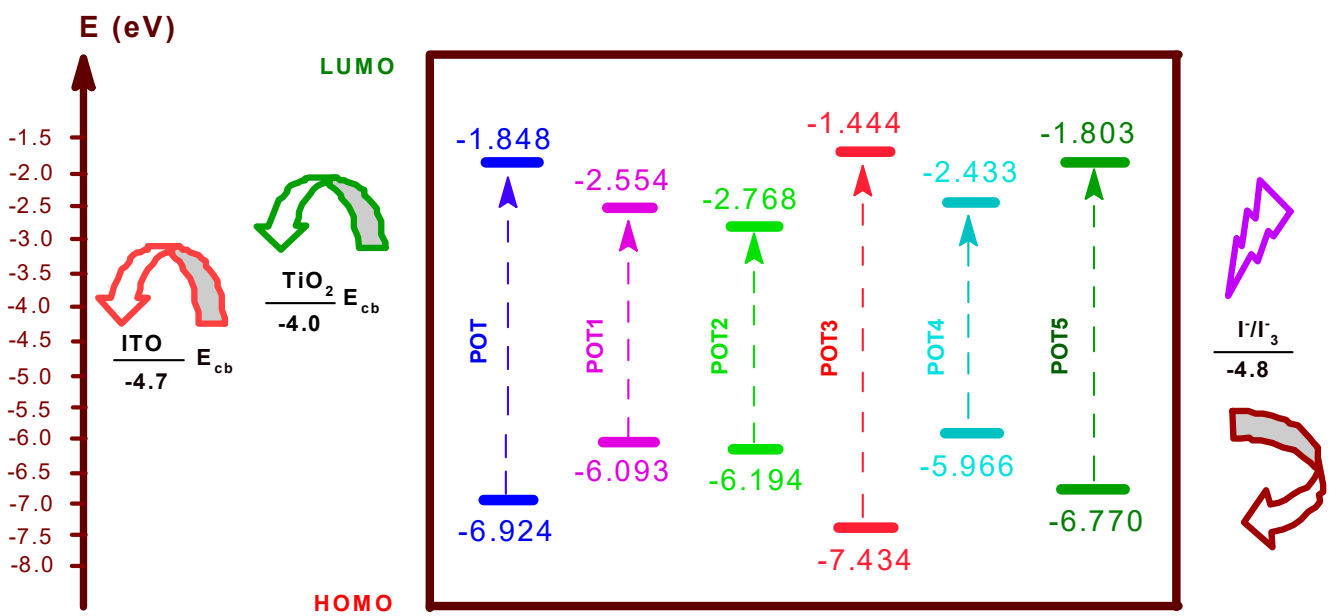

Fig.-5: Schematic Energy Diagram of Dyes, $\mathrm{TiO}_{2}$ and Electrolyte $\left(\mathrm{I}^{-} / \mathrm{I}_{3}^{-}\right)$. Eномо and $\mathrm{E}_{\mathrm{Lumo}}$ of the Dyes are in Gas Phase

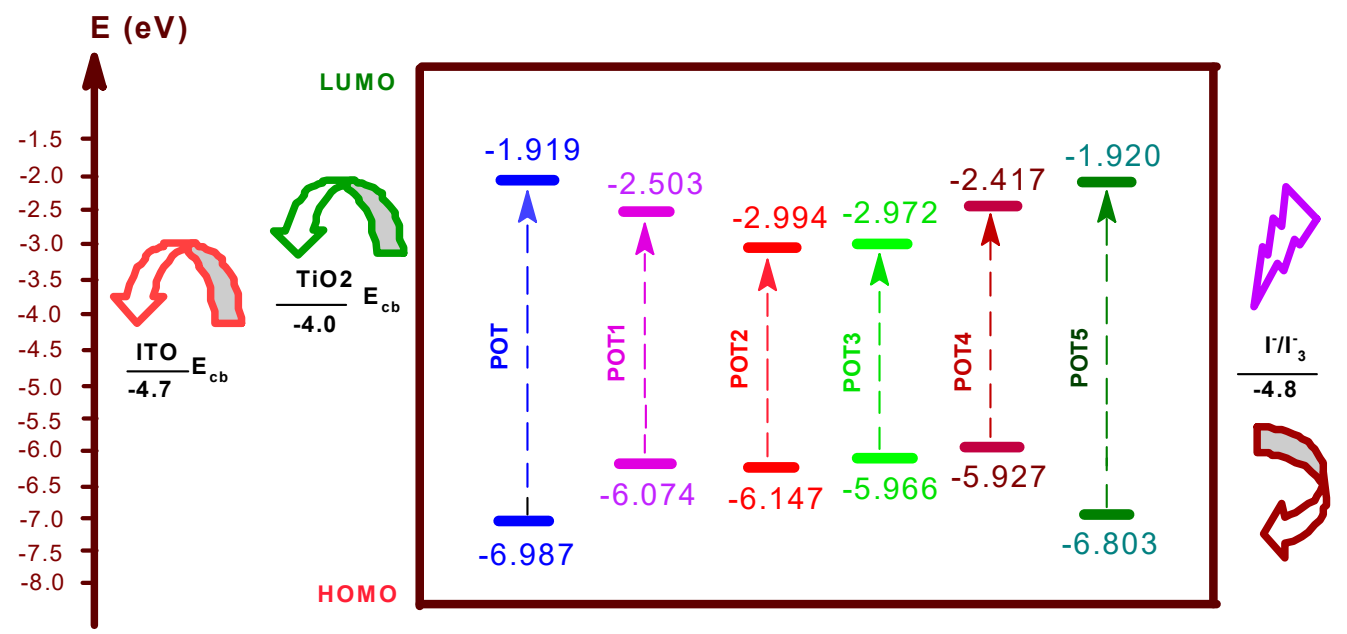

Fig.-6: Schematic Energy Diagram of Dyes, $\mathrm{TiO}_{2}$ and Electrolyte $\left(\mathrm{I}^{-} / \mathrm{I}_{3}{ }^{-}\right)$. $\mathrm{E}_{\mathrm{HO} O}$ and $\mathrm{E}_{\mathrm{Lumo}}$ of the Dyes are in DMF 
RASĀYAN J. Chem.

Vol. 14 | No. 3 |1875-1884| July - September | 2021

$\lambda_{\max }, \Delta \mathrm{G}_{\text {inject, }} E_{\text {ox }}^{\text {dye }}, E_{\text {ox }}^{d y e *}, \lambda_{\text {max }}^{I C T}$ are given in Table-2. In investigated derivatives then $\left|V_{R P}\right|$ and $\Delta \mathrm{G}_{\text {inject }}$ is superior as compared to the POT. The $\left|V_{R P}\right|$ and $\Delta \mathrm{G}_{\text {inject }}$ for POTs has been observed as 0.876 and 1.753 in the gas phase and 0.795 and -1.791 in DMF respectively. By comparing those values with newly designed dyes, it has been found that the newly designed dyes would be efficient sensitizers. The derivatives containing $\mathrm{CN}$ have superior LHE as compared to other systems. Based on the electron activating group, the trend to enhance LHE has been observed as $\mathrm{CN}>\mathrm{NO}_{2}$. We observed that systems having $\mathrm{COOH}$ as substituent has higher $\Delta \mathrm{G}_{\text {inject }}$ and $\left|V_{R P}\right|$ as compared to the derivatives containing $\mathrm{NO}_{2}$.

\section{UV-Vis Absorption Spectra}

An efficient photosensitizer exhibits intense absorption in the visible region (400 nm to $700 \mathrm{~nm}){ }^{30}$ The transition (HOMO to LUMO level) characters in the (DMF) solvent and gas phase are different. The oscillator strength also increases in the solvent phase differs from that of the gas phase in the studied molecules. The decrease in absorption wavelength in the solvent phase is due to the addition of polar solvent. $^{31}$

The simulated absorption spectra of the six POT dyes in the gas phase and solvent medium are shown in Fig.-7 and 8. The first optically allowed electronic transitions of POT, POT1, POT2, POT3, POT4, and POT5 are predicted to populate the HOMO $\rightarrow$ LUMO transitions at 265.09, 435.35, 453.18, 385.18436 .72 and 390.25 in the gas phase and 270.85, 427.53, 493.45, 504.97, 434.42 and $406.46 \mathrm{~nm}$ respectively for solvent medium. It seems that the calculated result reproduces the considerable redshift of the spectra in the solvent phase. Therefore, the inclusion of the solvent is important to calculate the spectra for considerable redshift.

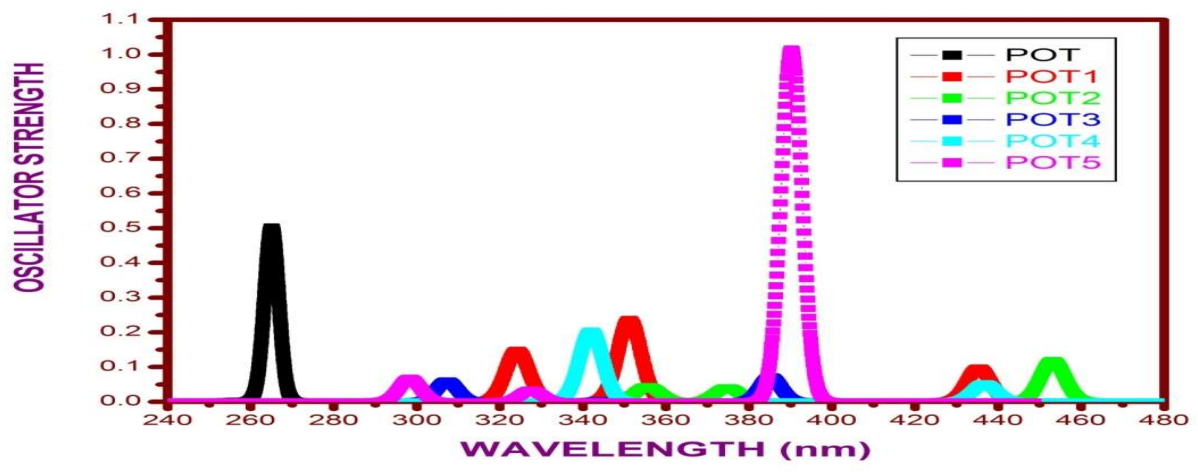

Fig.-7: Simulated Absorption Spectra of Dyes calculated in Gas Phase at TDDFT / B3LYP/6-311+G(d,p) Level of Theory

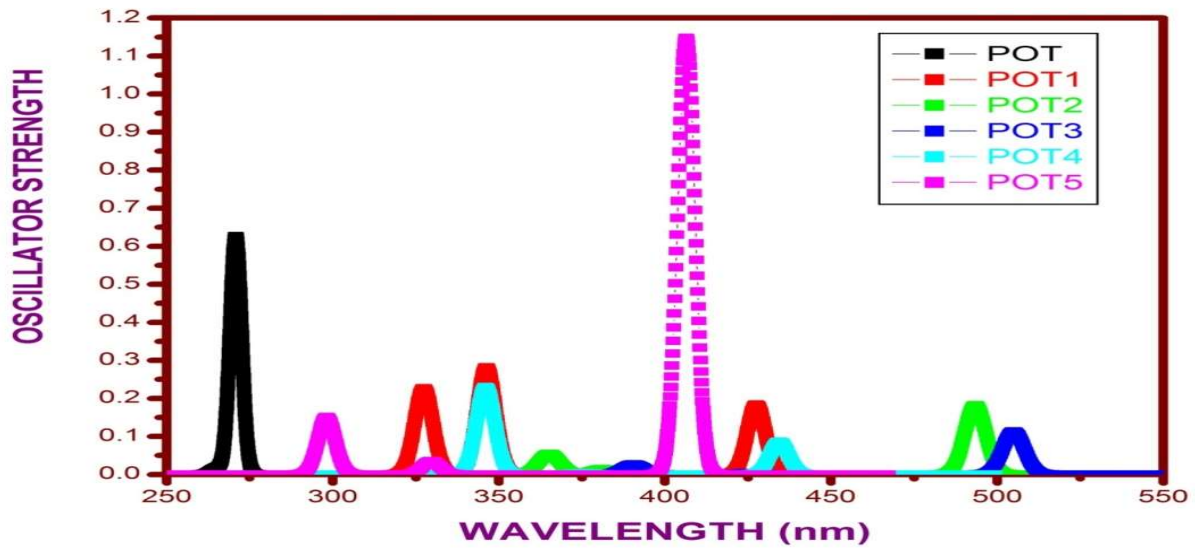

Fig.-8: Simulated Absorption Spectra of Dyes calculated in DMF at TDDFT / B3LYP/6-311+G(d,p) Level of Theory 
RASĀYAN J. Chem.

Vol. 14 | No. 3 |1875-1884| July - September | 2021

The structural modifications improving the electron injection efficiency of the POT-based DSSCs. Of course, all modifications are theoretically possible and a large panel of new structures can be tested. Therefore, we impose that all dyes possess terminal of either $\mathrm{C}_{2} \mathrm{H}_{4} \mathrm{~N}$ or $\mathrm{C}_{2} \mathrm{H}_{4} \mathrm{NO}_{2}$ group on the acceptor unit is necessary to link the dye to the semiconductor surface. In this work, it has been focused on and the free energy of injection $\left(\Delta \mathrm{G}_{\text {inject }}\right)$, the oxidation potential of the dye must be positive, and the light-harvesting efficiency of the dye to be as high as possible to maximize the photocurrent response. The comprehensive intramolecular charge transfer has been observed from the donor to the acceptor side. The diphenyl and triphenyl substitution in the donor site are favorable to enhance $\left(\Delta \mathrm{G}_{\text {inject }}\right)$ and $\left|V_{R P}\right|$.

Table-2: Calculated absorption spectra $\lambda_{\max } \mathrm{nm}, \Delta G^{\text {inject }}$, oxidation potential, intramolecular charge transfer energy of dyes at B3LYP/6-311+G level of energy

\begin{tabular}{|c|c|c|c|c|c|c|c|c|c|c|}
\hline \multirow{2}{*}{ System } & \multicolumn{5}{|c|}{ Gas Phase } & \multicolumn{5}{|c|}{ DMF } \\
\hline & $\lambda_{\max }$ & $\Delta G^{\text {inject }}$ & $E_{o x}^{d y e *}$ & $E_{o x}^{d y e}$ & $\lambda_{\max }^{I C T}$ & $\lambda_{\max }$ & $\Delta G^{\text {inject }}$ & $E_{o x}^{d y e *}$ & $E_{o x}^{d y e}$ & $\lambda_{\max }^{I C T}$ \\
\hline POT & 265.09 & -1.753 & 2.247 & 6.924 & 4.677 & 270.85 & -1.591 & 2.409 & 6.987 & 4.578 \\
\hline POT1 & 435.35 & -0.754 & 3.246 & 6.093 & 2.847 & 427.53 & -0.827 & 3.173 & 6.073 & 2.900 \\
\hline POT2 & 453.18 & -0.541 & 3.459 & 6.194 & 2.735 & 493.45 & -0.367 & 3.633 & 6.146 & 2.513 \\
\hline POT3 & 385.18 & 0.215 & 4.215 & 7.434 & 3.219 & 504.97 & -0.480 & 3.511 & 5.966 & 2.455 \\
\hline POT4 & 436.72 & -0.873 & 3.127 & 5.966 & 2.839 & 434.42 & -0.928 & 3.072 & 5.926 & 2.854 \\
\hline POT5 & 390.25 & -0.407 & 3.593 & 6.770 & 3.177 & 406.46 & -0.254 & 3.746 & 6.802 & 3.050 \\
\hline
\end{tabular}

\section{Light-Harvesting Efficiency (LHE) and Oscillator Strength}

The light-harvesting efficiency (LHE) is the efficiency of the dye to respond to the light. It is another factor that indicates the efficiency of DSSC. The light-harvesting efficiency (LHE) of the dye should be as high as possible to increase the photocurrent response. The LHE of all the dyes is calculated and listed in Table3. The LHE of all the dyes in the gas phase is in the range of 0.057 to 0.489 and in the DMF, they are in the range of 0.118 to 0.504 . The LHE values for the dyes are in a narrow range. As a result of Light-harvesting efficiency, the POT5 has been observed to be 0.489 and 0.503 in the gas phase and solvent medium respectively. Thus, it has been concluded that the introduction of amine derivatives in the donor side enhances the LHE and it is nicely comparable with the earlier studies. These dyes will convert more light into electricity.

Table-3: Excitation energy (E), Light Harvesting Efficiency (LHE) and Average Light Harvesting Efficiency (LHE Average) of dyes at B3LYP/6-311+G level of theory

\begin{tabular}{|c|c|c|c|c|c|c|c|c|}
\hline \multirow[t]{2}{*}{ System } & \multicolumn{4}{|c|}{ Gas Phase } & \multicolumn{4}{|c|}{ DMF } \\
\hline & $\mathrm{E}(\mathrm{eV})$ & $\lambda(\mathrm{nm})$ & LHE & $L H E_{\text {avg }}$ & $\mathrm{E}(\mathrm{eV})$ & $\lambda(\mathrm{nm})$ & LHE & $L H E_{\text {avg }}$ \\
\hline \multirow{2}{*}{ POT } & 4.6771 & 265.09 & 0.683 & \multirow{2}{*}{0.352} & 4.5777 & 270.85 & 0.764 & \multirow{2}{*}{0.401} \\
\hline & 4.7155 & 262.93 & 0.021 & & 4.6792 & 264.97 & 0.037 & \\
\hline \multirow{2}{*}{ POT1 } & 2.8479 & 435.35 & 0.201 & \multirow{2}{*}{0.311} & 2.9000 & 427.53 & 0.345 & \multirow{2}{*}{0.411} \\
\hline & 3.5301 & 351.22 & 0.421 & & 3.5802 & 346.30 & 0.477 & \\
\hline \multirow{2}{*}{ POT2 } & 2.7359 & 453.18 & 0.239 & \multirow{2}{*}{0.163} & 2.5126 & 493.45 & 0.343 & \multirow{2}{*}{0.187} \\
\hline & 3.3076 & 374.85 & 0.088 & & 3.2526 & 381.19 & 0.032 & \\
\hline \multirow{2}{*}{ РОT3 } & 3.2189 & 385.18 & 0.153 & \multirow{2}{*}{0.080} & 2.4553 & 421.97 & 0.229 & \multirow{2}{*}{0.118} \\
\hline & 3.5878 & 345.57 & 0.008 & & 2.9174 & 335.73 & 0.008 & \\
\hline \multirow{2}{*}{ POT4 } & 2.8390 & 436.72 & 0.113 & \multirow{2}{*}{0.057} & 2.8540 & 434.42 & 0.179 & \multirow{2}{*}{0.209} \\
\hline & 3.2770 & 378.35 & 0.001 & & 3.3008 & 375.62 & 0.007 & \\
\hline \multirow{2}{*}{ POT5 } & 3.1771 & 390.25 & 0.904 & \multirow{2}{*}{0.489} & 3.0503 & 406.46 & 0.929 & \multirow{2}{*}{0.504} \\
\hline & 3.7854 & 327.53 & 0.074 & & 3.7605 & 329.70 & 0.078 & \\
\hline
\end{tabular}

The oscillator strength is directly obtained from DFT calculation. The POT dye has two main absorption peaks (265 and $390 \mathrm{~nm}$ in the gas phase, 270 and $406 \mathrm{~nm}$ in solvent phase DMF). The oscillator strength and transition character are given in Table-4. Only the transition with considerable oscillator strengths is given. The electron structure of the four newly designed sensitizers is quite similar to one another even though their substituent is different. 
RASĀYAN J. Chem.

Vol. 14 | No. 3 |1875-1884| July - September | 2021

Table-4: Oscillator strength (f) and Transition character of dyes ( $\mathrm{H}=\mathrm{HOMO} \mathrm{L}=\mathrm{LUMO}, \mathrm{L}+1=\mathrm{LUMO}+1$, etc) at B3LYP/6-311+G level of theory

\begin{tabular}{l|l|l|l|l|l|l}
\hline \multirow{2}{*}{ System } & \multicolumn{3}{|c|}{ Gas Phase } & \multicolumn{3}{c}{ DMF } \\
\cline { 2 - 7 } & $\lambda(\mathrm{nm})$ & $\mathrm{f}$ & Transition character & $\lambda(\mathrm{nm})$ & $\mathrm{f}$ & Transition character \\
\hline \multirow{3}{*}{ POT } & 265.09 & 0.4991 & $\mathrm{H} \rightarrow \mathrm{L}(100 \%)$ & 270.85 & 0.6268 & $\mathrm{H} \rightarrow \mathrm{L}(100 \%)$ \\
\cline { 2 - 7 } & 262.93 & 0.0091 & $\mathrm{H}-1 \rightarrow \mathrm{L}(90.6 \%)$ & 264.97 & 0.0164 & $\mathrm{H}-1 \rightarrow \mathrm{L}(91.8 \%)$ \\
\cline { 2 - 7 } & 257.21 & 0.0016 & $\mathrm{H} \rightarrow \mathrm{L}+1(89.01 \%)$ & 246.50 & 0.0007 & $\mathrm{H} \rightarrow \mathrm{L}+1(85.4 \%)$ \\
\hline \multirow{3}{*}{ POT1 } & 435.35 & 0.0973 & $\mathrm{H} \rightarrow \mathrm{L}(100 \%)$ & 427.53 & 0.1839 & $\mathrm{H} \rightarrow \mathrm{L}(100 \%)$ \\
\cline { 2 - 7 } & 351.22 & 0.2370 & $\mathrm{H} \rightarrow \mathrm{L}+1(86.8 \%)$ & 346.30 & 0.2818 & $\mathrm{H} \rightarrow \mathrm{L}+1(85.1 \%)$ \\
\cline { 2 - 7 } & 324.21 & 0.1483 & $\mathrm{H}-1 \rightarrow \mathrm{L}(79.5 \%)$ & 327.42 & 0.2268 & $\mathrm{H}-1 \rightarrow \mathrm{L}(80.2 \%)$ \\
\hline \multirow{3}{*}{ POT2 } & 453.18 & 0.1189 & $\mathrm{H} \rightarrow \mathrm{L}(100 \%)$ & 493.45 & 0.1823 & $\mathrm{H} \rightarrow \mathrm{L}(100 \%)$ \\
\cline { 2 - 7 } & 374.85 & 0.0404 & $\mathrm{H} \rightarrow \mathrm{L}+1(84.5 \%)$ & 381.19 & 0.0140 & $\mathrm{H} \rightarrow \mathrm{L}+1(79.3 \%)$ \\
\cline { 2 - 7 } & 355.61 & 0.0439 & $\mathrm{H}-1 \rightarrow \mathrm{L}(80 \%)$ & 365.22 & 0.0543 & $\mathrm{H}-1 \rightarrow \mathrm{L}(78.8 \%)$ \\
\hline \multirow{3}{*}{ POT4 } & 385.27 & 0.0722 & $\mathrm{H} \rightarrow \mathrm{L}(100 \%)$ & 504.97 & 0.1134 & $\mathrm{H} \rightarrow \mathrm{L}(100 \%)$ \\
\cline { 2 - 7 } & 345.57 & 0.0036 & $\mathrm{H}-1 \rightarrow \mathrm{L}(78.3 \%)$ & 424.98 & 0.0038 & $\mathrm{H} \rightarrow \mathrm{L}+1(81.11 \%)$ \\
\cline { 2 - 7 } & 307.28 & 0.0600 & $\mathrm{H}-1 \rightarrow \mathrm{L}+1(66.5 \%)$ & 390.55 & 0.0265 & $\mathrm{H}-1 \rightarrow \mathrm{L}(78.85 \%)$ \\
\cline { 2 - 7 } & 436.72 & 0.0521 & $\mathrm{H} \rightarrow \mathrm{L}(100 \%)$ & 434.42 & 0.0861 & $\mathrm{H} \rightarrow \mathrm{L}(100 \%)$ \\
\cline { 2 - 7 } & 378.35 & 0.0006 & $\mathrm{H}-1 \rightarrow \mathrm{L}(87.6 \%)$ & 375.62 & 0.0029 & $\mathrm{H}-1 \rightarrow \mathrm{L}(86.1 \%)$ \\
\cline { 2 - 7 } POT5 & 342.00 & 0.2038 & $\mathrm{H}-1 \rightarrow \mathrm{L}+1(82.6 \%)$ & 346.06 & 0.2298 & $\mathrm{H}-1 \rightarrow \mathrm{L}+1(82.3 \%)$ \\
\cline { 2 - 7 } & 390.25 & 1.0161 & $\mathrm{H} \rightarrow \mathrm{L}(100 \%)$ & 406.46 & 1.1480 & $\mathrm{H} \rightarrow \mathrm{L}(100 \%)$ \\
\cline { 2 - 7 } & 327.53 & 0.0334 & $\mathrm{H} \rightarrow \mathrm{L}+1(81.6 .1 \%)$ & 329.70 & 0.0353 & $\mathrm{H} \rightarrow \mathrm{L}+1(81.1 \%)$ \\
\cline { 2 - 7 } & 298.35 & 0.0676 & $\mathrm{H}-1 \rightarrow \mathrm{L}(79.1 \%)$ & 298.18 & 0.1510 & $\mathrm{H}-1 \rightarrow \mathrm{L}(78.9 \%)$ \\
\hline
\end{tabular}

\section{Transition Character}

Based on the analysis of the electron density of HOMO and LUMO, all the absorption behaviors of the dyes can be ascribed to the intramolecular charge transfer (ICT) character. The maximum absorption peak of POT and POT1 is located at 265.09 and $435.35 \mathrm{~nm}$, respectively, which is contributed by the HOMO $\rightarrow$ LUMO transition. The HOMO-1 of POT and POT1 is located at 262.93 and $324.21 \mathrm{~nm}$ respectively. Thus, it is reasonable to assign the 262.93 and $324.21 \mathrm{~nm}$ for POT and POT1 ICT characters. Similarly, the HOMO-1 of POT2 and POT3 is located at 355.61 and $345.57 \mathrm{~nm}$ respectively, and the HOMO-1 of POT4 and POT5 is located at 378.35 and $321 \mathrm{~nm}$ respectively. From the above calculations, it can be seen that all the absorption peaks of POT to POT5 are covering the entire visible region, which makes these dyes suitable for the application of DSSC.

Table-5: The electron injection $\left(\Delta G^{\text {inject }}\right)$, relative electron injection $\left(\Delta G_{r}^{\text {inject }}\right)$, oxidation potentials, light harvesting efficiencies (LHE), electron coupling constants $\left(\left|\mathrm{V}_{R P}\right|\right)$, absorption $\left(\lambda_{\max }\right)$ in nm, oscillator strengths (f) and transitions of POT dyes.

\begin{tabular}{l|l|l|l|l|l|l|l|l|l}
\hline System & $\Delta G^{\text {inject }}$ & $E_{\text {ox }}^{\text {dye }}$ & $E_{\text {ox }}^{\text {dye* }}$ & $\lambda_{\max }^{I C T}$ & $\mathrm{f}$ & LHE & $\Delta G_{r}^{\text {inject }}$ & $\lambda_{\max }$ & $\left|\mathrm{V}_{R P}\right|$ \\
\hline POT & -1.591 & 6.987 & 2.409 & 4.578 & 0.627 & 0.764 & 1.000 & 270.85 & 0.796 \\
\hline POT1 & -0.827 & 6.073 & 3.173 & 2.900 & 0.184 & 0.345 & 0.520 & 427.53 & 0.413 \\
\hline POT2 & -0.367 & 6.146 & 3.633 & 2.513 & 0.182 & 0.343 & 0.231 & 493.45 & 0.183 \\
\hline POT3 & -0.480 & 5.966 & 3.511 & 2.455 & 0.113 & 0.229 & 0.302 & 504.97 & 0.240 \\
\hline POT4 & -0.928 & 5.926 & 3.072 & 2.854 & 0.086 & 0.179 & 0.583 & 434.42 & 0.464 \\
\hline POT5 & -0.254 & 6.802 & 3.746 & 3.050 & 1.148 & 0.929 & 0.160 & 406.46 & 0.127 \\
\hline
\end{tabular}

\section{CONCLUSION}

The UV-Visible spectroscopic properties, as well as the free energy of injection of systems POT- POT5, show that these dyes are the potential to be a good photosensitizer in DSSC. According to thermodynamic the spontaneous charge transfer process from the dye in an excited state to the conduction band of metal oxide need the LUMO energy of the dye to be more positive potential than the conduction band energy of metal oxide while the HOMO energy of the dye must be negative than reduction potential energy of the electrolyte. The superior electron injection and electron coupling constants of investigated systems are revealing that these derivatives show better DSSC properties. It can also be observed that by elongating the 
bridge, the HOMO and LUMO energy gap decreases in 5-phenyl-1,3,4-oxadiazole 2-thiol. By using this theoretical procedure to gain insights into the geometrical and electronic structures of the dyes and bring out the adequate structural modification that will optimize the properties of the 5-phenyl-1,3,4-oxadiazole 2-thiol based dye-sensitized solar cells. Therefore, it can be concluded that further chemical modification of the dye such as adding high effective anchoring groups, bridges, or electron donor groups could raise the electron injection and light-harvesting efficiency of the DSSC with these photosensitizers.

\section{REFERENCES}

1. B. O' Reagen and M. Gratzel, Nature, 353, 737(1991), https://doi.org/10.1038/353737a0

2. A. Goetzeger and C. Hebling, Solar Energy Materials and Solar Cells, 62, 1(2000), https://doi.org/10.1016/S0927-0248(99)00131-2

3. A. Hagfeldt, M. Graetzel, Chemical Reviews, 95 (1), 49(1995), https://doi.org/10.1021/cr00033a003

4. M. Graetzel, Nature, 414 (6861), 338(2001), https://doi.org/10.1038/35104607

5. T.A. Heimer, E.J. Heilweil, C.A. Bignozzi, G.j. Meyer, The Journal of Physical Chemistry A, 104 4256(2000), https://doi.org/10.1021/jp993438y

6. Nazeeruddin, M.K. Michael graetzel festschrift, Coordination Chemistry Reviews, 248, 1161(2004).

7. P.V. Kamat, M. Haria, S. Hotchandani, The Journal of Physical Chemistry B, 108, 5166(2004), https://doi.org/10.1021/jp0496699

8. J. Bisquert, D. Cahen, G. Hodes, S. Ruehle, A. Zaban, The Journal of Physical Chemistry B, 108 (24), 8106(2004), https://doi.org/10.1021/jp0359283

9. A. Furube, R. Katoh, T.Yoshihara, K. Hara, S. Murata, H. Arakawa, M. Tachiya, The Journal of Physical Chemistry B, 108, 12583(2004), https://doi.org/10.1021/jp0487713

10. A. Mishra, M.k. Fischer, P. Bayerle, Angewandte Chemie International Edition, 48(14), 2474(2009), https://doi.org/10.1002/anie.200804709

11. D. Liu, R.W. Fessenden, G.L. Hug, and P.V. Kamat, The Journal of Physical Chemistry B, 101(14), 2583(1997), https://doi.org/10.1021/jp962695p

12. B. Burfeindt, T. Hannappel, W. Storck, and F. Willig, The Journal of Physical Chemistry, 100(41), 16463(1996), https://doi.org/10.1021/jp9622905

13. K. Sayama, S. Tsukagochi, K. Hara, Y. Ohga, A. Shinpou, Y. Abe, S. Suga, H. Arakawa, The Journal of Physical Chemistry B, 106, 1363(2002), https://doi.org/10.1021/jp0129380

14. Z. Ning, Q. Zhang, W. Wu , H. Pei , B. Liu, H. Tian, Journal of Organic Chemistry, 73(10), 3791(2008), https://doi.org/10.1021/jo800159t

15. Sandra M. Feldt, Elizabeth A. Gibson, Erik Gabrielsson, Licheng Sun, Gerrit Boschloo and Anders Hagfeldt, Journal of the American Chemical Society, 132(46), 16714(2010), https://doi.org/10.1021/ja1088869

16. T.Horiuchi, H. Miura, K. Sumioka, S,J. Uchida, Journal of the American Chemical Society, 126, 39, 12218(2004), https://doi.org/10.1021/ja0488277

17. A.Furube, R.Katoh, T. Yoshihara, K. Hara, S.Murata, H.Arakawa, M.Tachiya, The Journal of Physical Chemistry B., 108,12588(2004), https://doi.org/10.1021/jp0487713

18. M. Frisch, J. et al. Gaussian 09, Revision A.1. Gaussian Inc, Wallingford, CT, 2009.

19. R. Katoh, A. Furube, T. Yoshihara, K. Hara, G. Fujihashi, S. Takano, S. Murata, H. Arakawa, M. Tachiya, The Journal of Physical Chemistry B, 108, 4818(2004), https://doi.org/10.1021/jp031260g

20. Nalwa, H. S. Handbook of Advanced Electronic and Photonic Materials and Devices; Academic: San Diego, 2001.

21. M. Liang and J. Chen, Chemical Society Reviews, 42(8), 3453(2013), https://doi.org/10.1039/C3CS35372A

22. W. Xu, B. Peng, J. Chen, M. Liang, and F. Cai, Journal of Physical Chemistry C, 112(3), 874(2008), https://doi.org/10.1021/jp076992d

23. M. Liang, W. Xu, F. Cai et al., Journal of Physical Chemistry C, 111(11), 4465(2007), https://doi.org/10.1021/jp067930a

24. H.-Q. Xia, J. Wang, F.-Q. Bai, and H.-X. Zhang, Dyes and Pigments, 113, 87(2015), https://doi.org/10.1016/j.dyepig.2014.07.033 
Vol. 14 | No. 3 |1875-1884| July - September | 2021

25. Muhammad Ramzan Saeed Ashraf Janjua, Journal of the Chilean Chemical Society, 63, 1 (2018), https://doi.org/10.4067/s0717-97072018000103850

26. Imelda, Emriadi, Aziz H, Santoni. A, Utami. N, Rasayan Journal of Chemistry, 13(1), 121(2020), https://doi.org/10.31788/RJC.2019.1245449

27. Chundan Lin, Yanbing Liu, Di Shao, Guochen Wang, Huiying Xu, Changjin Shao, Wansong Zhang and Zhenqing Yang, RSC Advances, 11, 3071(2021), https://doi.org/10.1039/D0RA08815C

28. Kadali Chaitanya, Xue-Hai Ju and B. Mark Heron, RSC Advances, 5, 3978(2015), https://doi.org/10.1039/C4RA09914A

29. Kadali Chaitanya, Xue-Hai Ju and B. Mark Heronb, RSC Advances, 4, 26621(2014), https://doi.org/10.1039/C4RA02473G

30. Umer Mehmood, Ibnelwaleed, A. Hussein, Khalil Harrabi and Shakeel Ahmed, Advances in Materials Science and Engineering, 286730, (2015), https://doi.org/10.1155/2015/286730

31. Juma Mzume Juma, Said Ali H. Vuai, N. Surendra Babu, International Journal of Photoenergy, 4616198, (2019), https://doi.org/10.1155/2019/4616198

[RJC-6501/2021] 